\title{
Prediction of Trained Panel Sensory Scores for Beef with Non-Invasive Raman Spectroscopy
}

\author{
Jamie Cafferky ${ }^{1,2}\left(\mathbb{D}\right.$, Raquel Cama-Moncunill ${ }^{1}{ }^{(D)}$, Torres Sweeney ${ }^{2} \mathbb{D}$, Paul Allen ${ }^{1}$, Andrew Cromie ${ }^{3}$ \\ and Ruth M. Hamill ${ }^{1, *}$
}

1 Department of Food Quality and Sensory Science, Teagasc Food Research Centre, Ashtown, D15 DY05 Dublin, Ireland; jamie.cafferky@teagasc.ie (J.C.); rql.cama@gmail.com (R.C.-M.); paul.allen869@gmail.com (P.A.)

2 School of Veterinary Medicine, University College Dublin, Belfield, D04 V1W8 Dublin, Ireland; torres.sweeney@ucd.ie

3 Irish Cattle Breeding Federation, Shinagh House, Bandon, P72 X050 Co. Cork, Ireland; acromie@icbf.com

* Correspondence: ruth.hamill@teagasc.ie

Citation: Cafferky, J.;

Cama-Moncunill, R.; Sweeney, T.; Allen, P.; Cromie, A.; Hamill, R.M. Prediction of Trained Panel Sensory Scores for Beef with Non-Invasive Raman Spectroscopy. Chemosensors 2022, 10, 6. https://doi.org/10.3390/ chemosensors10010006

Academic Editor: Ambra Giannetti

Received: 31 October 2021

Accepted: 21 December 2021

Published: 25 December 2021

Publisher's Note: MDPI stays neutral with regard to jurisdictional claims in published maps and institutional affiliations.

Copyright: (C) 2021 by the authors. Licensee MDPI, Basel, Switzerland. This article is an open access article distributed under the terms and conditions of the Creative Commons Attribution (CC BY) license (https:/ / creativecommons.org/licenses/by/ $4.0 /)$.

\begin{abstract}
The objective of this study was to investigate Raman spectroscopy as a tool for the prediction of sensory quality in beef. Raman spectra were collected from M. longissimus thoracis et lumborum (LTL) muscle on a thawed steak frozen $48 \mathrm{~h}$ post-mortem. Another steak was removed from the muscle and aged for 14 days before being assessed for 12 sensory traits by a trained panel. The most accurate coefficients of determination of cross validation $\left(R^{2} C V\right)$ calibrated within the current study were for the trained sensory panel textural scores; particularly tenderness $(0.46)$, chewiness $(0.43)$, stringiness (0.35) and difficulty to swallow (0.33), with practical predictions also achieved for metallic flavour (0.52), fatty after-effect (0.44) and juiciness (0.36). In general, the application of mathematical spectral pretreatments to Raman spectra improved the predictive accuracy of chemometric models developed. This study provides calibrations for valuable quality traits derived from a trained sensory panel in a non-destructive manner, using Raman spectra collected at a time-point compatible with meat management systems.
\end{abstract}

Keywords: Raman spectroscopy; chemometrics; beef quality; trained sensory panel; tenderness

\section{Introduction}

Sensory characteristics have a major influence on consumer eating satisfaction with regard to repurchasing fresh meat $[1,2]$. The most direct and accurate method of evaluating the sensory attributes of meat is through the use of trained panels [3,4]. However, sensory panels are expensive and time consuming to conduct [5]. Consequently, these methods are difficult to implement for either routine quality monitoring within meat management systems by commercial meat processors [6], or large scale, industry-wide recording of beef sensory data for the purposes of genetic evaluations [7].

Raman spectroscopy is a non-invasive vibrational spectroscopic technique that has applications in prediction of food quality. Raman spectroscopy measures the light scattered inelastically resulting from the interaction of a laser light with the molecules of a sample. Inelastic scattered light consists of photons that have experienced an energy/wavelength shift with respect to the incident light due to molecular vibrations. Therefore, the energy/wavelength shift is characteristic of the molecules present and can be used as a 'chemical fingerprint' of a sample [6]. Raman spectroscopy has numerous practical advantages in the context of food quality monitoring, including rapid measurement time, simple preparation of sample and non-destructive analysis, while providing high resolution detailed spectral information [3,8,9]. Another major advantage of Raman spectroscopy is its suitability for on-line implementation due to the use of fibre optics [10]. Moreover, it is relatively insensitive to water (in comparison to other technologies such as visible and near 
infrared spectroscopy), rendering it suitable for application in the modelling/prediction of meat-eating quality traits [11].

The available literature is sparse in regard to the prediction of meat-trained sensory panel scores using Raman spectroscopy $[4,8,9]$. However, Raman spectroscopy has demonstrated its relevance to many areas of meat research. For example, it has been used successfully for the evaluation of meat spoilage [12,13], prediction of ultimate $\mathrm{pH}$ in pork [13], prediction of pork IMF content [14] and instrumental tenderness, IMF, cookloss $\%$ and drip-loss $\%$ in beef $[15,16]$. Based on the demonstrated potential of Raman to capture the chemical signals associated with animal fat in terms of intramuscular fat and variability in ion content (in terms of $\mathrm{pH}$ in meat), and given the chemical nature of at least some sensory traits, we hypothesise that Raman spectroscopy would have potential for predicting meat eating quality. The objective of this study was to assess the potential of Raman spectroscopy as a tool for in-factory rapid prediction of meat eating quality. To this end, we collected non-destructive spectra on 2-day-aged beef samples and trained sensory panel scores from 14-day-aged beef samples from the same muscle, and conducted chemometric modelling of Raman spectra in relation to a range of sensory traits.

\section{Materials and Methods}

\subsection{Animals and Sample Preparation}

Crossbred bull and steer progeny $(n=595,18 \pm 4$ months old) samples were collected [17]. Based on capturing maximal near infrared spectral variability within this data set [7], a subset of these animals $(n=110)$ were selected for sensory and Raman spectral analysis.

At $24 \mathrm{~h}$ post-mortem carcasses were quartered, and at $48 \mathrm{~h}$ post-mortem loins were boned out. Twelve steaks with a thickness of $2.54 \mathrm{~cm}$ were sliced from the right-side $L T L$ starting at the anterior end, and vacuum packed. These steaks were labelled 1-12 in order of cutting. This step was included to ensure measurements were collected at a consistent location on the loin each time. The 5th and 6th steak removed from the loin were used for trained sensory panel analysis, while the 12th steak was allocated for Raman spectroscopy.

Samples allocated for Raman spectroscopy analysis were blast frozen at $-20^{\circ} \mathrm{C}$ and stored frozen until Raman spectra acquisition. Samples allocated for sensory analysis were aged in vacuum bags to 14 days post-mortem in a chill room set at $4{ }^{\circ} \mathrm{C}$, then blast frozen at $-20^{\circ} \mathrm{C}$ and stored frozen until sensory analysis.

\subsection{Raman Spectral Measurements}

Prior to collection of spectra, LTL samples were thawed in a circulating water bath at room temperature. Once thawed, steaks were removed from the water bath, removed from vacuum packaging and lightly blotted with paper to remove excess surface moisture. Steaks were then wrapped tightly with oxygen-permeable clingfilm wrap, taking care not to trap air bubbles between the clingfilm wrap and LTL sample surface. Raman spectra were collected using a DXR SmartRaman spectrometer (ThermoFisher Scientific UK Ltd., Loughborough, UK) equipped with a diode laser operating at $780 \mathrm{~nm}$, a charge-coupled device (CCD) detector and a universal platform sampling (UPS) accessory with a slit-aperture of $50 \mu \mathrm{m}$. The muscle was scanned on the transverse surface of the LTL, in 10 representative locations ( 5 scans per side) within the muscle free from excessive fat and connective tissue. Raman intensity counts per second were recorded over the $250-3381 \mathrm{~cm}^{-1} \mathrm{Ra}-$ man shift range with $2 \mathrm{~cm}^{-1}$ intervals via OMNIC for Dispersive Raman 9.2.98 software (ThermoFisher Scientific UK Ltd., Loughborough, UK). The scanning settings employed were: $120 \mathrm{~mW}$ laser power, $15 \mathrm{~s}$ exposure time and 10 exposures. Cosmic spikes were automatically removed by the software.

\subsection{Sensory Analysis}

Sensory analysis was conducted at Teagasc Ashtown (Dublin 15, Ireland), following a modified version of the American Meat Science Association Research Guidelines for Cookery, Sensory Evaluation and Instrumental Tenderness Measurements of Meat [18]. 
Twelve sensory traits were scored (tenderness, juiciness, chewiness, stringiness, crumbly texture, fatty mouthfeel, difficulty to swallow, beef flavour, metallic flavour, beef after-effect, metallic aftereffect and fatty after-effect) on a 0-100 line scale, with 0 being the lowest score and 100 the highest. A detailed description of this method is provided in Cafferky et al. [7].

\subsection{Chemometric Analysis}

Spectral pre-processing and data analysis were performed with the statistical application R (R Core Team, 2018) using the R packages, (baseline, signal, EMSC, pls, plsVarSel and other in-house functions). Calculations were based on Raman shift ranges from 3100 to $700 \mathrm{~cm}^{-1}$, as a low signal-to-noise ratio was observed outside this range. Two ranges were evaluated: $3100-700 \mathrm{~cm}^{-1}$ and $1800-700 \mathrm{~cm}^{-1}$. For the prediction of beef sensory attributes, partial least squares regression (PLSR) models were developed for each of the 12 sensory and textural traits analysed (Y data), using Raman spectra collected from intact LTL samples (X data), with 104 models constructed in this study in total. Variable importance on projection (VIP) was employed as the algorithm of choice for variable selection [19]. VIP was conducted with a 1 threshold and iteratively (backwards variable elimination) until the minimum root mean square error of cross validation (RMSECV) was obtained. Four spectral pre-treatments were evaluated in the current study as follows: Extended multiplicative scatter correction (EMSC); Savitzky-Golay first derivative, second-degree polynomial with nine smoothing points (SG1); Savitzky-Golay second derivative, second-degree polynomial with nine smoothing points (SG2); and baseline correction (polynomial of 5th order). PLSR models were calibrated using the kernel algorithm, with the performance of models evaluated using twenty iterations of a ten-fold cross validation. Parameters examined in model performance evaluation included coefficient of determination of calibration $\left(R^{2} C\right)$, coefficient of determination of cross validation $\left(\mathrm{R}^{2} \mathrm{CV}\right)$, root mean square error of calibration (RMSEC) and root mean square error of cross-validation (RMSECV).

\section{Results and Discussion}

\subsection{Descriptive Statistics of Sensory Traits}

Descriptive statistics for the 12 beef sensory traits are presented in Table 1. Large coefficients of variation were present in the textural sensory traits of chewiness, crumbliness, stringiness and difficulty to swallow (CV 46.5\% to 80.8\%); and also for the flavour-related traits of metallic flavour, metallic after-effect, fatty mouthfeel and fatty after-effect (CV $40.8 \%$ to $77 \%$ ). Lower variability among samples was observed for juiciness, tenderness, beef flavour and beef after-effect (17.5\% to $23.1 \%)$.

Table 1. Descriptive statistics of twelve beef LTL eating quality traits (sensory scores measured on a scale of $0-100)$.

\begin{tabular}{ccccccc}
\hline & Mean & SD & Median & Min & Max & CV \\
\hline Tenderness & 51.85 & 11.98 & 54.91 & 23.25 & 70.75 & $23.1 \%$ \\
Chewiness & 26.98 & 12.55 & 23.35 & 6.83 & 56.33 & $46.5 \%$ \\
Stringiness & 12.31 & 9.95 & 8.81 & 0.43 & 40.94 & $80.8 \%$ \\
Difficulty to swallow & 12.25 & 8.09 & 10.14 & 0.83 & 33.13 & $66.0 \%$ \\
Crumbliness & 20 & 11.21 & 17.63 & 2.33 & 45.3 & $56.1 \%$ \\
Beefflavour & 41.16 & 7.22 & 41.27 & 20.6 & 60.88 & $17.5 \%$ \\
Beef AE & 31.2 & 5.76 & 31.23 & 16.5 & 45 & $18.5 \%$ \\
Juiciness & 33.51 & 7.06 & 33.2 & 17.5 & 54.35 & $21.1 \%$ \\
Fatty mouthfeel & 5.96 & 4.56 & 4.63 & 0.21 & 19.63 & $76.5 \%$ \\
Fatty AE & 6.38 & 4.91 & 5 & 0.5 & 24.25 & $77.0 \%$ \\
Metallic flavour & 13.91 & 5.9 & 12.77 & 1.42 & 29.5 & $42.4 \%$ \\
Metallic AE & 18.49 & 7.54 & 18.65 & 3.67 & 37.63 & $40.8 \%$ \\
\hline
\end{tabular}

SD, Standard Deviation; Min, Minimum; Max, Maximum; CV, Coefficient of Variation; $A E$, After-effect; Sensory scores are measured on a scale of $0-100$.

\subsection{Prediction of Beef LTL Sensory Tenderness by Raman Spectroscopy}

To evaluate the potential of Raman spectroscopy for prediction of beef sensory quality, PLSR models were developed for each sensory trait using various pre-processing techniques 
and Raman shift ranges. Models based on the Raman shift range from 1800 to $700 \mathrm{~cm}^{-1}$ resulted in increased predictive ability. This effect was attributed to the fact that the range from 1800 to $500 \mathrm{~cm}^{-1}$ contains most of the relevant Raman scattering responses of meat [16]. Average spectra for the five highest and five lowest performing samples for tenderness, chewiness and crumbliness may be seen in Supplementary file Figure S1.

The best-fitting prediction models for each beef sensory and textural traits using Raman spectroscopy are presented in Table 2. It is widely considered that tenderness is the most important sensory trait for consumers, with first bite tenderness the basis on which many consumers make a decision on whether they will re-purchase [20], while at the same time consistently being the trait most difficult to predict without destruction of the sample [9]. Best-fitting models for prediction of tenderness gave moderate results $\left(R^{2} C V=0.46\right.$; RMSECV = 8.74). EMSC was found to be more effective than SG pre-processing for prediction of tenderness, with both models calibrated using two latent variables (LV). Indeed, the best fitting models for all traits presented in the current study were all calibrated within the first two LV.

Table 2. Best fitting predictions of twelve sensory traits on beef LTL using Raman spectral measurements.

\begin{tabular}{|c|c|c|c|c|c|c|c|}
\hline Variable & Math Treatment & Var & $P$ & $\mathbf{R}^{2}$ Cal & RMSEC & $\mathrm{R}^{2} \mathrm{CV}$ & RMSECV \\
\hline \multirow[t]{2}{*}{ Tenderness } & EMSC & 131 & 2 & 0.66 & 6.92 & 0.46 & 8.74 \\
\hline & SG2 & 265 & 2 & 0.61 & 7.41 & 0.33 & 9.74 \\
\hline \multirow[t]{2}{*}{ Chewiness } & EMSC & 119 & 2 & 0.64 & 7.54 & 0.43 & 9.46 \\
\hline & SG2 & 255 & 2 & 0.59 & 8.05 & 0.34 & 10.15 \\
\hline \multirow[t]{2}{*}{ Stringiness } & EMSC & 120 & 1 & 0.46 & 7.31 & 0.35 & 7.96 \\
\hline & SG1 & 69 & 3 & 0.46 & 7.27 & 0.35 & 7.97 \\
\hline \multirow[t]{2}{*}{ Diff. swallow } & SG2 & 270 & 2 & 0.61 & 5.03 & 0.33 & 6.59 \\
\hline & EMSC & 358 & 1 & 0.51 & 5.67 & 0.33 & 6.62 \\
\hline \multirow[t]{2}{*}{ Crumbliness } & EMSC & 126 & 1 & 0.45 & 8.27 & 0.36 & 8.92 \\
\hline & SG2 & 244 & 2 & 0.49 & 7.96 & 0.31 & 9.28 \\
\hline \multirow[t]{2}{*}{ Beef flavour } & EMSC & 149 & 1 & 0.36 & 5.77 & 0.22 & 6.36 \\
\hline & SG2 & 286 & 2 & 0.54 & 4.87 & 0.16 & 6.60 \\
\hline \multirow[t]{2}{*}{ Beef $A E$} & EMSC & 391 & 1 & 0.42 & 4.35 & 0.27 & 4.91 \\
\hline & SG2 & 233 & 2 & 0.53 & 3.92 & 0.14 & 5.32 \\
\hline \multirow{2}{*}{ Juiciness } & SG2 & 275 & 2 & 0.60 & 4.43 & 0.36 & 5.63 \\
\hline & EMSC & 132 & 2 & 0.60 & 4.46 & 0.30 & 5.88 \\
\hline \multirow[t]{2}{*}{ Fatty mouthfeel } & EMSC & 353 & 1 & 0.51 & 3.19 & 0.34 & 3.70 \\
\hline & SG2 & 286 & 2 & 0.58 & 2.94 & 0.31 & 3.76 \\
\hline \multirow[t]{2}{*}{ Fatty $A E$} & EMSC & 338 & 1 & 0.41 & 2.90 & 0.23 & 3.31 \\
\hline & SG2 & 265 & 2 & 0.70 & 2.08 & 0.44 & 2.82 \\
\hline \multirow[t]{2}{*}{ Metallic flavour } & SG2 & 258 & 2 & 0.70 & 3.25 & 0.52 & 4.08 \\
\hline & EMSC & 128 & 1 & 0.45 & 4.35 & 0.35 & 4.74 \\
\hline \multirow[t]{2}{*}{ Metallic AE } & EMSC & 128 & 1 & 0.5 & 5.33 & 0.37 & 5.94 \\
\hline & SG2 & 212 & 2 & 0.54 & 5.08 & 0.28 & 6.37 \\
\hline
\end{tabular}

Var, number of spectral variables retained by Variable Importance in Projection; $P$, number of PLS terms utilised in the calibration of the equation; $\mathrm{R}^{2} \mathrm{C}$, coefficient of determination of calibration; RMSEC, root mean square error of calibration; $\mathrm{R}^{2} \mathrm{CV}$, coefficient of determination of cross validation; RMSECV, root mean square error of cross validation; Diff. Swallow, Difficulty to swallow; AE, after-effect; EMSC, Extended multiplicative scatter correction; SG1, Savitzky-Golay first derivative, second-degree polynomial with nine smoothing points; SG2, Savitzky-Golay second derivative, second-degree polynomial with nine smoothing points.

The correlation between Raman spectra and tenderness scores (trained sensory panel) was evaluated based on the loading plot values obtained for PLS factors 1 and 2 (Figure 1a). This plot provides information on the Raman bands that contributed to each PLS factor [21]. The plot identified a series of bands that contribute to the prediction of tenderness, most of which are related to $\beta$-sheet folding; an example of this are the bands from 1680 to $1665 \mathrm{~cm}^{-1}$ [3]. Both PLS factors 1 and 2 indicate that this region is positively correlated to tenderness. This is noteworthy, since higher prevalence of $\beta$-sheet structures in meat are associated with toughness, rather than tenderness [3,22]. Yet, higher intensity at the region $1685-1645 \mathrm{~cm}^{-1}$ may be due to contribution from lipids such as the $C=C$ stretching mode occurring around 1680-1640 cm. Higher fat content has been previously associated with an increase in meat tenderness. PLS factor 2 also indicates that the band situated at $962 \mathrm{~cm}^{-1}$, which is associated with $\mathrm{C}-\mathrm{C}$ stretching vibrations of random coil, is negatively correlated 
to tenderness scores [3,22]. Furthermore, PLS factor 1 indicates that the band at $1263 \mathrm{~cm}^{-1}$, which may be attributed to the presence of connective tissue [15], has a negative correlation to tenderness. Other prominent bands correlated to tenderness scores include the 1322 and $1354 \mathrm{~cm}^{-1}$ band related to asymmetrical $\mathrm{SO}_{2}$ stretching and the bands visible at 1605,1617 , 1658 and $1784 \mathrm{~cm}^{-1}$, which are located within the primary thioamides-Amide II band [23].

The samples analysed in the current study (for the prediction of trained sensory panel scores for beef via Raman spectroscopy) are a subset of a larger group of samples analysed in a study investigating the use of visible-near infrared spectroscopy (VISNIRS) for the prediction of trained sensory panel scores for beef [7]. When comparing our previous predictions of sensory tenderness using VISNIRS to Raman spectroscopy, Raman spectroscopy predictions outperform VISNIRS prediction in nearly every parameter (VISNIRS $\mathrm{R}^{2} \mathrm{CV}=0.13$; RMSECV $=8.6 ; \mathrm{LV}=6$ ).

This study is novel in the context of Raman prediction of tenderness, because we recorded spectra on uncooked, intact muscle, at an early time point post-mortem. This makes the process highly relevant to the need for rapid online predictions characteristic of the meat industry, which rarely have the facilities to age, cook and/or homogenise samples for the prediction of sensory attributes prior to sale. Beattie et al. [3] developed models for trained sensory panel tenderness scores of beef silverside, however in that study, spectral collection and sensory panel analysis were both carried out on 21-day-aged and cooked beef. While the prediction was slightly more accurate in that study $\left(R^{2}=0.65\right)$, it came with a larger error value (RMSECV =9.69). Furthermore, our rapid prediction at 2 days post-mortem would be more relevant for industrial application in terms of furthering rapid technologies to aid meat management strategies and animal breeding for meat quality. The predictive ability of the model for beef tenderness presented in the current study $\left(R^{2} C V=0.46\right)$, which was found on meat aged for only $2 \mathrm{~d}$, has superior potential for integration into routine process analytical monitoring in meat plants. Zhao et al. [9] reported a similar prediction for tenderness $\left(\mathrm{R}^{2} \mathrm{CV}=0.45\right)$ to our study, but they calibrated models using Raman spectra collected from homogenised beef samples. Our study demonstrates that the predictive accuracy of models calibrated using Raman spectra for tenderness is not improved through meat homogenisation (though this may be more relevant for traits associated with fat content, such as juiciness and flavour).

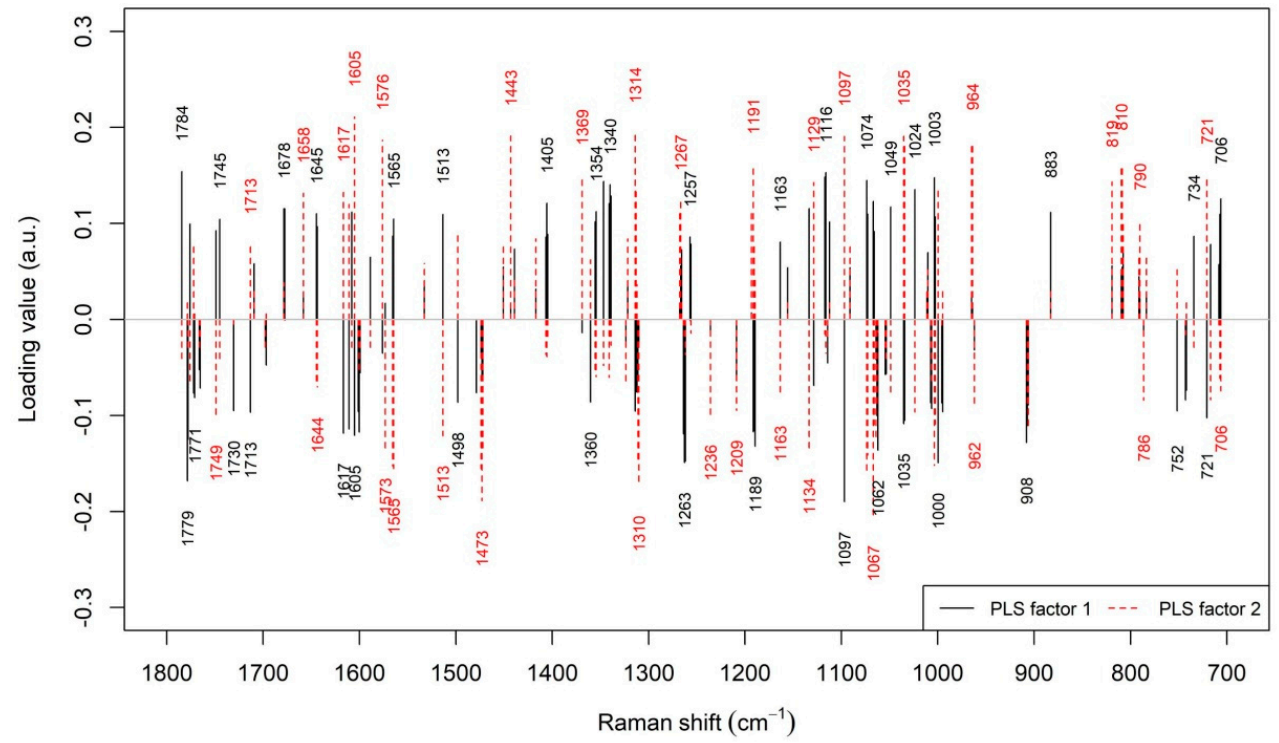

(a)

Figure 1. Cont. 


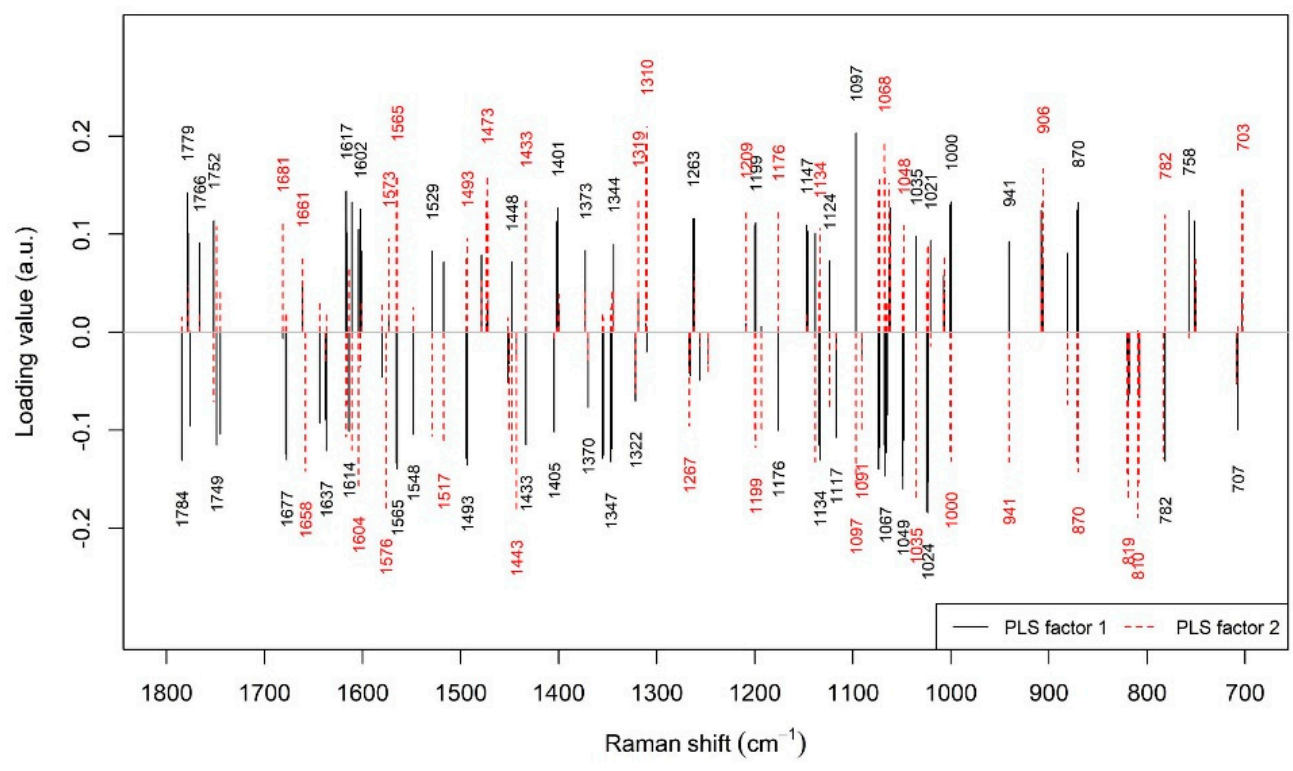

(b)

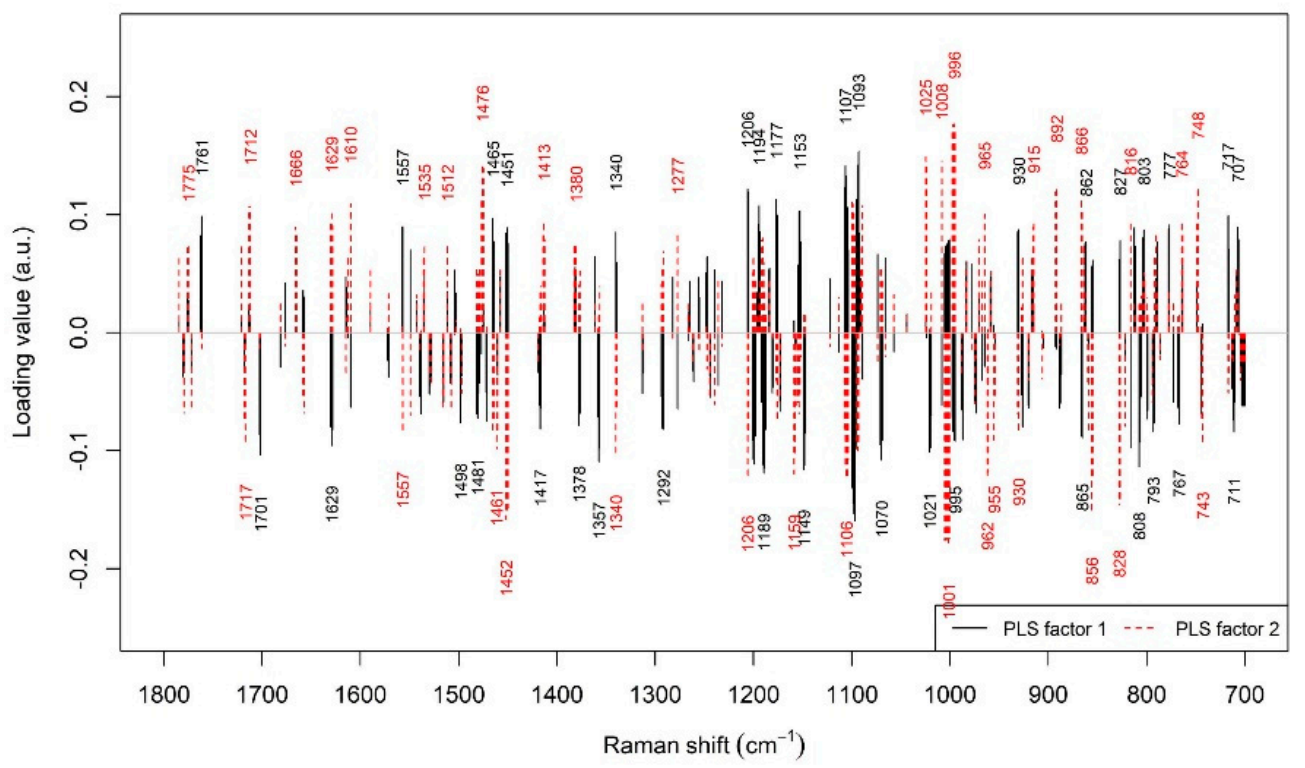

(c)

Figure 1. Cont. 


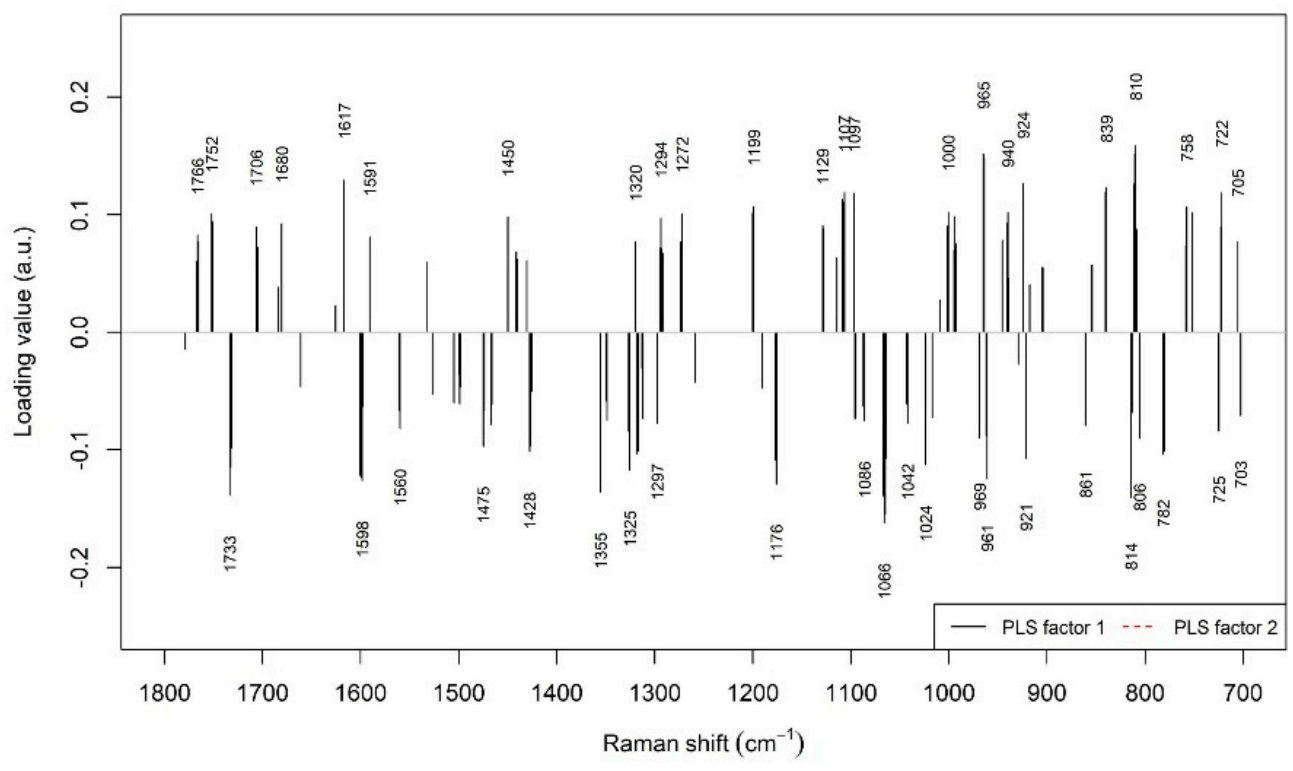

(d)

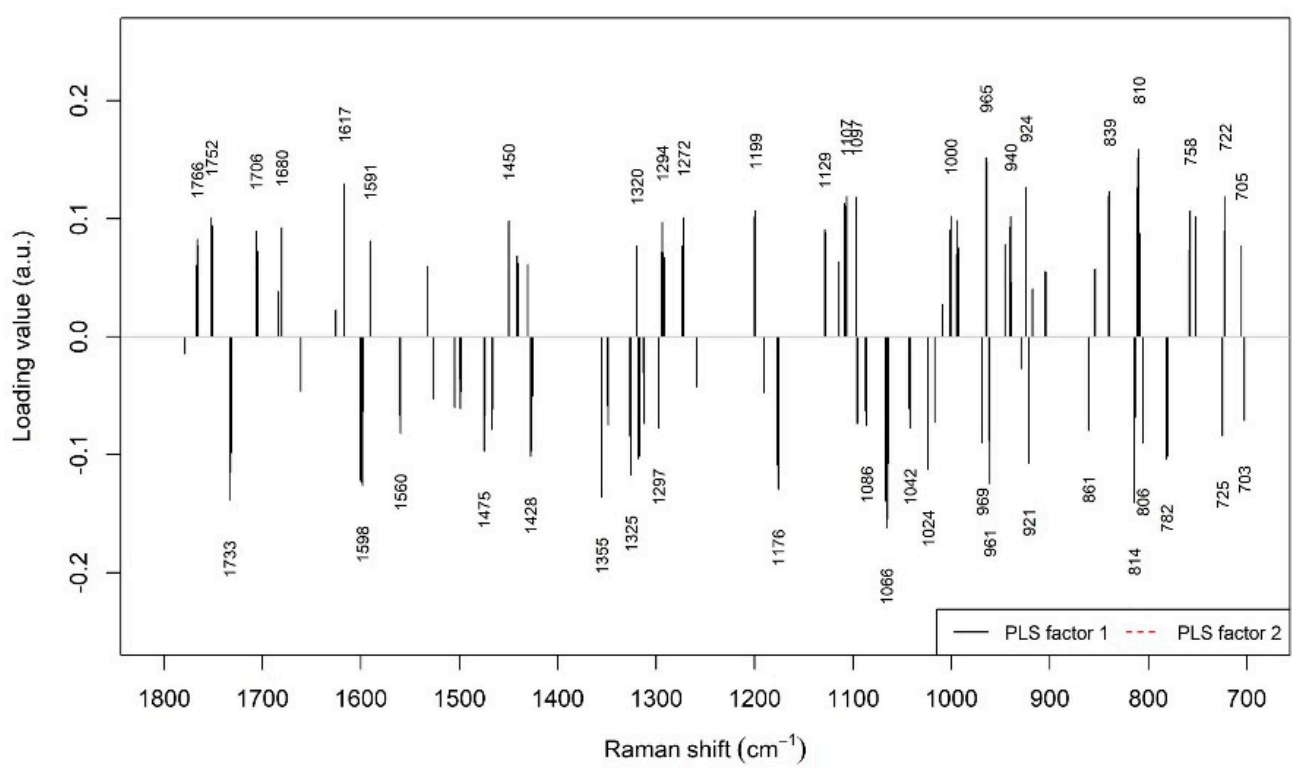

(e)

Figure 1. Cont. 


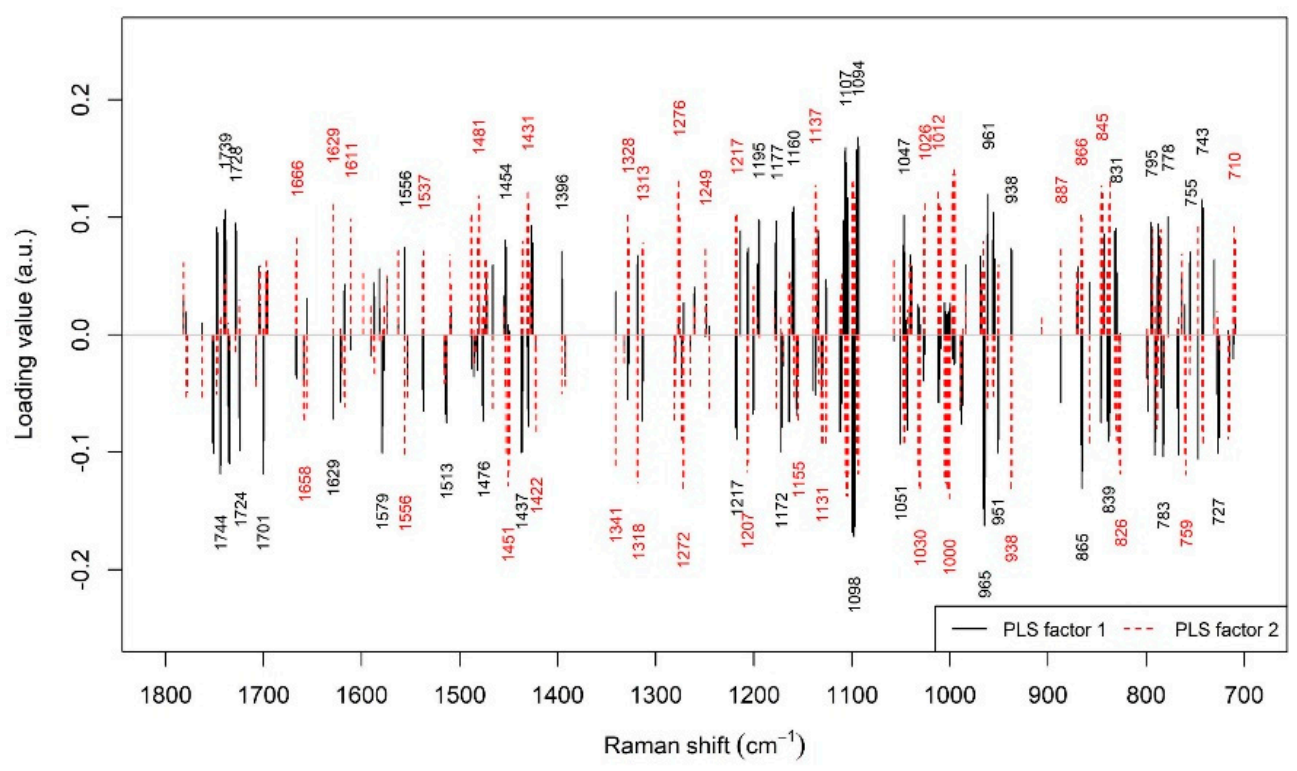

(f)

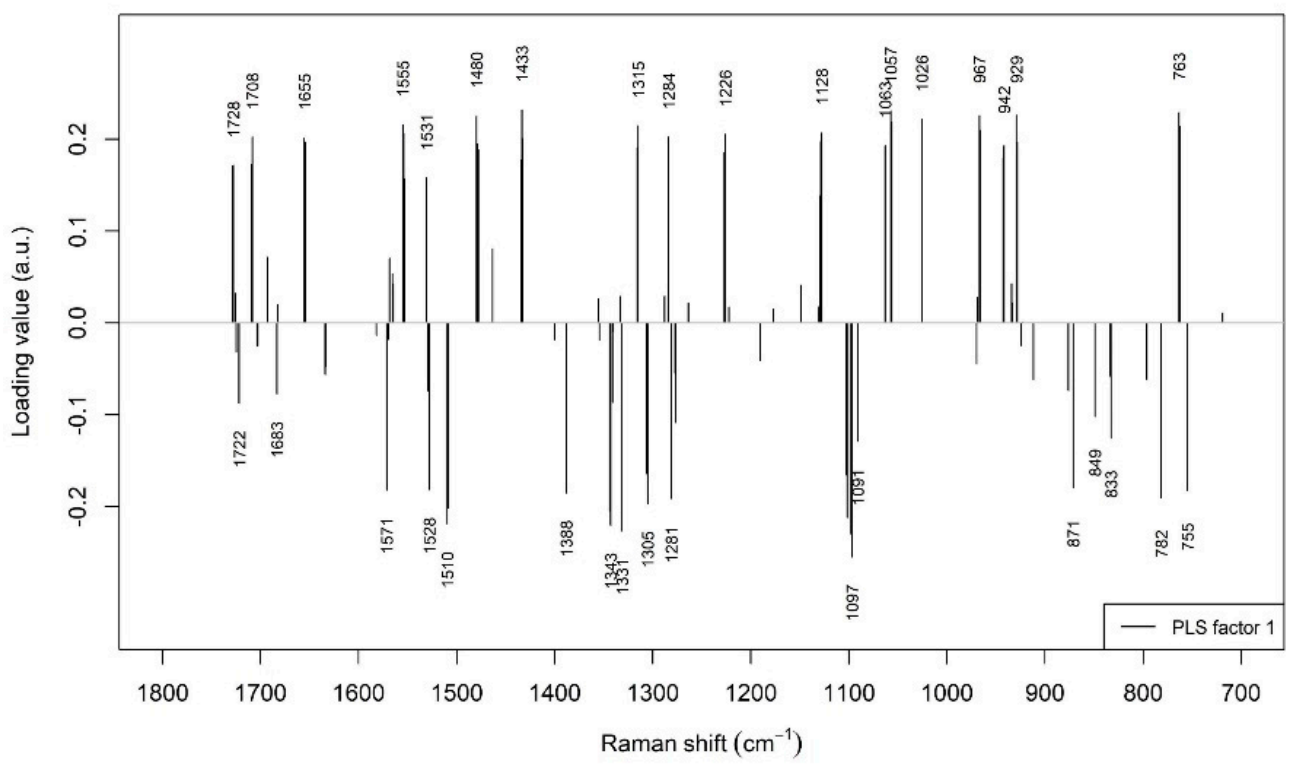

(g)

Figure 1. Cont. 


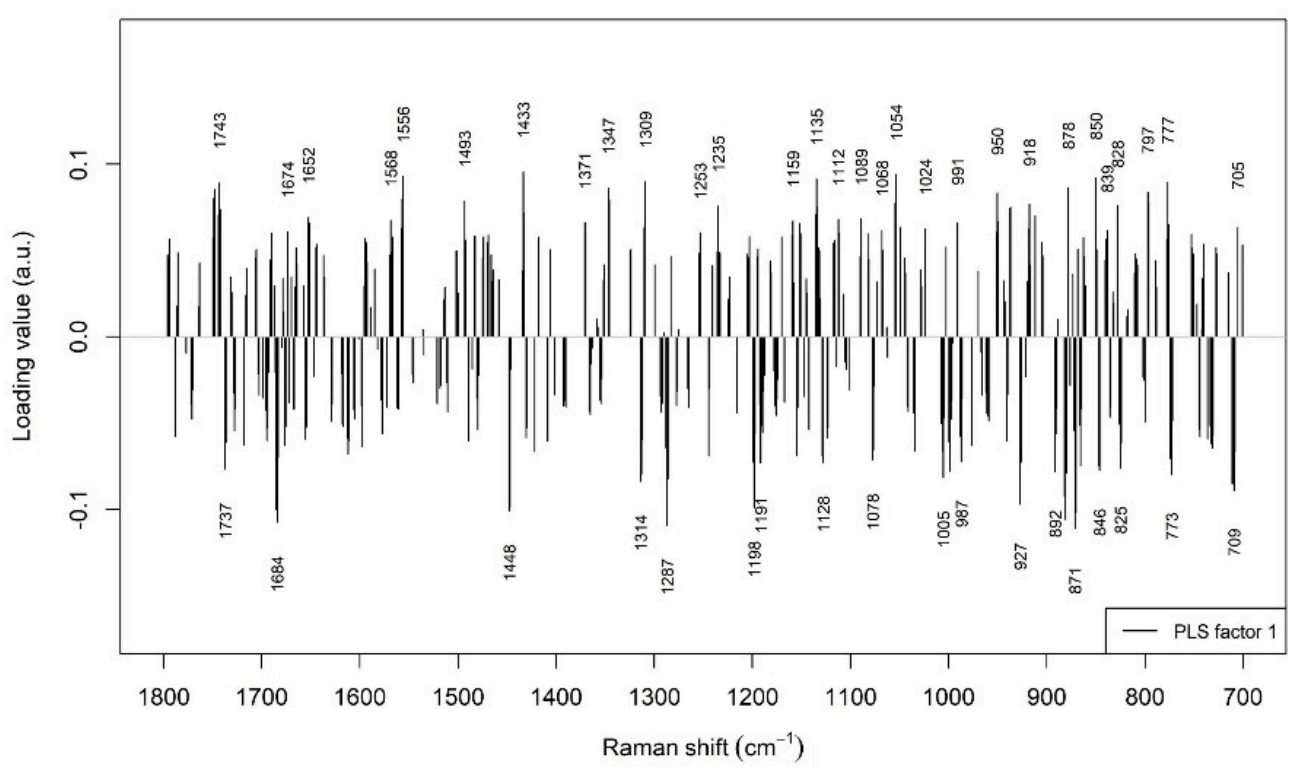

(h)

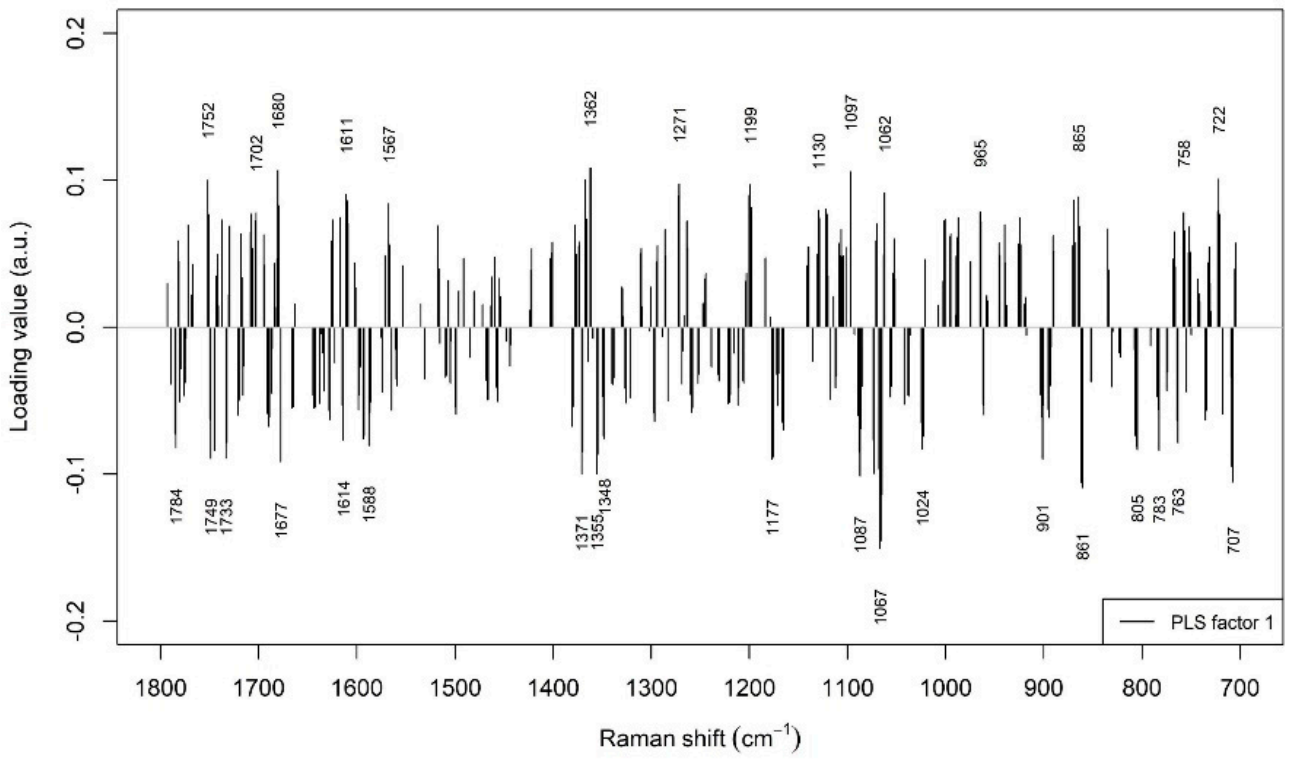

(i)

Figure 1. Cont. 


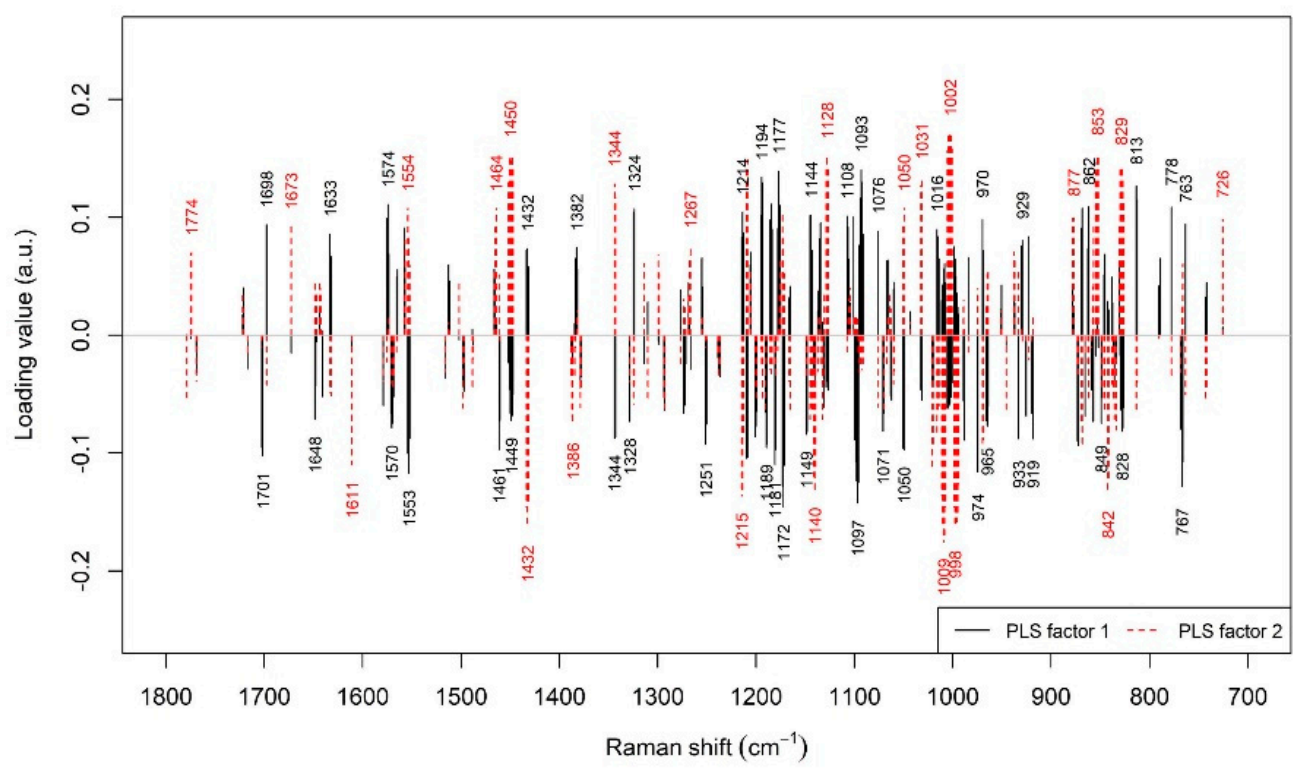

(j)

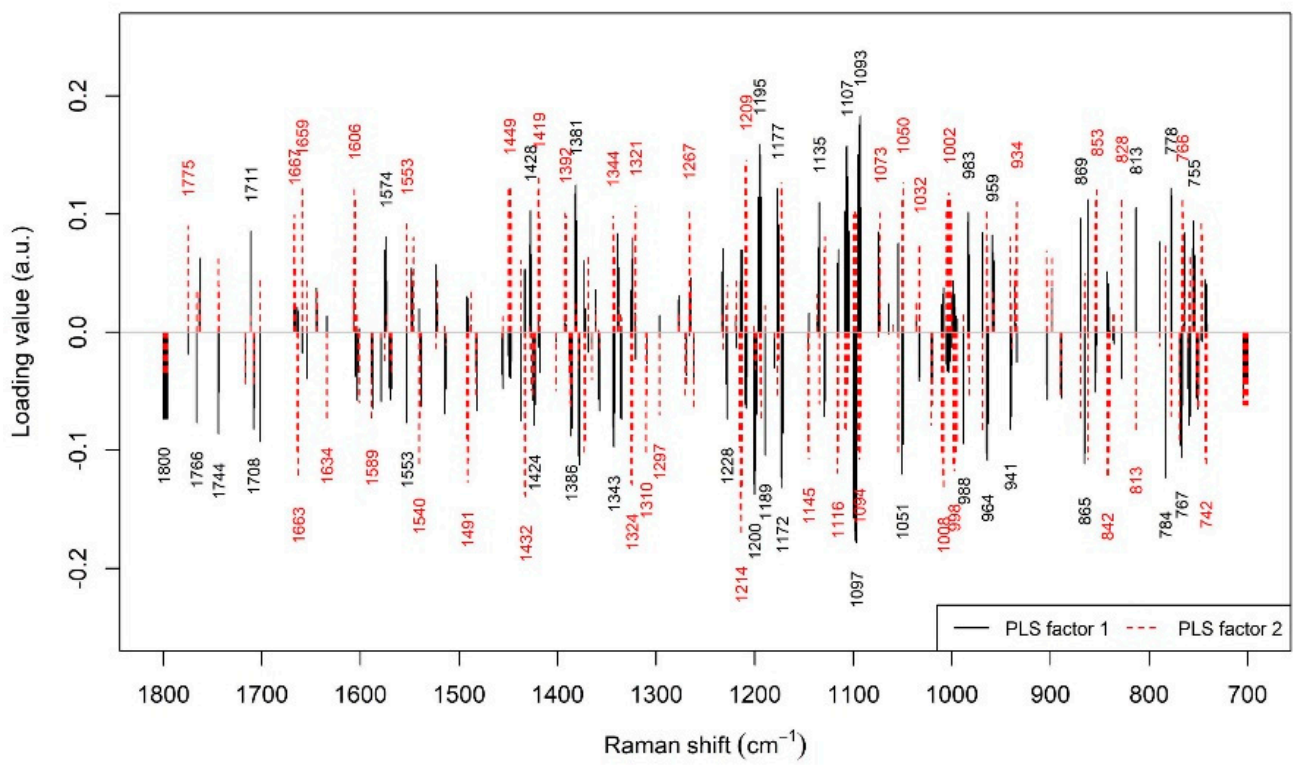

(k)

Figure 1. Cont. 


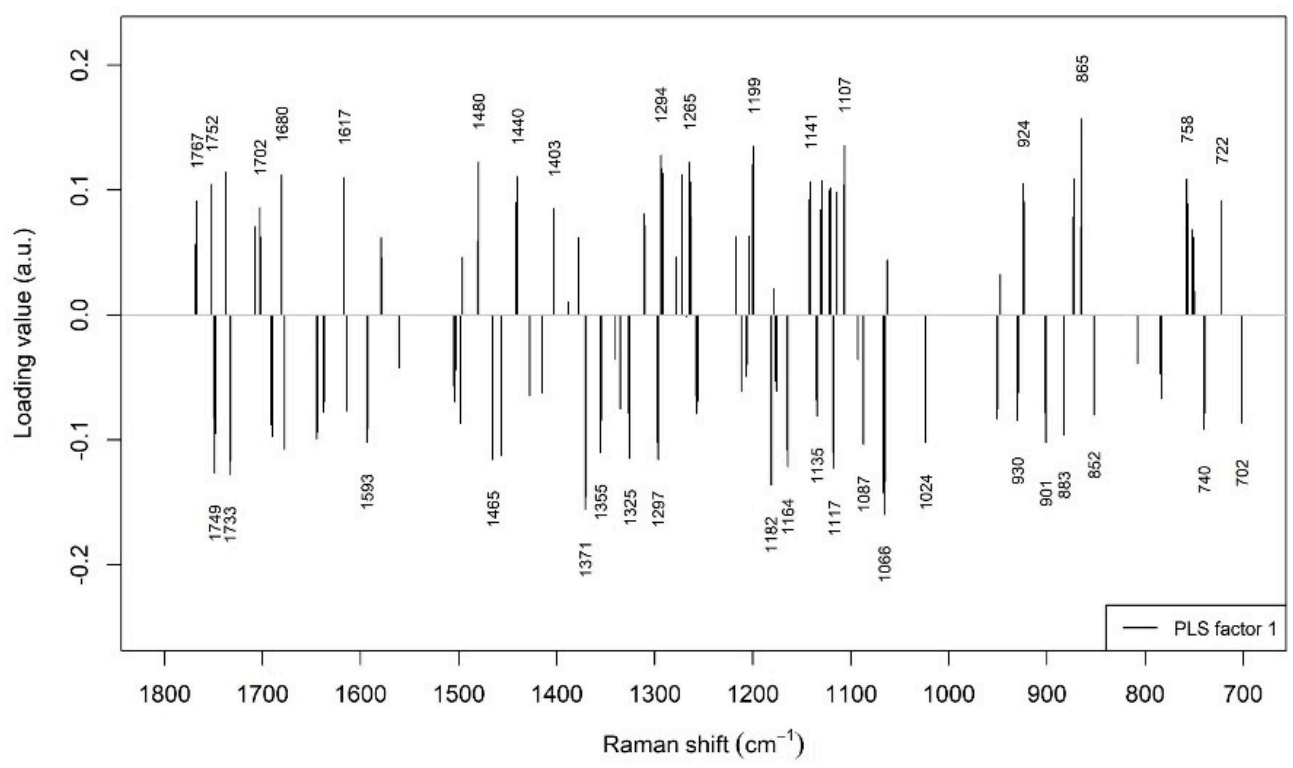

(1)

Figure 1. Loading values of first/first two PLS factors employed by the selected models for (a) tenderness, (b) chewiness, (c) stringiness, (d) difficulty to swallow, (e) crumbliness, (f) juiciness, (g) beef flavour, (h) beef after-effect, (i) fatty mouthfeel, (j) fatty after-effect, (k) metallic flavour, (1) metallic after-effect.

\subsection{Prediction of Other Beef LTL Textural Traits by Raman Spectroscopy}

Traditionally, trained beef sensory panels only score samples on traits such as tenderness, flavour and juiciness, with the occasional exception of chewiness included. With the insight and feedback of the trained sensory panel (after undergoing initial training and screening), the number of traits to be analysed was expanded (particularly in regards to texture) in an effort to subdivide the entire sensory profile of our samples to try to provide novel and more refined predictions that the wider meat industry could use in the future for more detailed selection for meat quality.

The textural sensory traits most commonly associated with toughness-chewiness, stringiness and difficulty to swallow, were also predicted with reasonable accuracy (Table 2). Of these three traits, chewiness was predicted with the highest accuracy $\left(R^{2} C V=0.43\right.$; RMSECV = 9.46; LV = 2). Difficulty to swallow and stringiness models calibrated using Raman spectra gave similar results $\left(R^{2} \mathrm{CV}=0.33 ; 0.35\right)$, with the difficulty to swallow model having slightly lower RMSECV values (6.62 and 7.96). Both models were calibrated in the first PLS term $(L V=1)$, suggesting that they were robust and repeatable.

In comparison to previous predictions of sensory meat quality traits using VISNIRS by our group [7], Raman spectroscopy outperformed VISNIRS in traits related to texture (VISNIRS $R^{2} C V$ difficulty to swallow $=0.1$; chewiness $=0.17$; stringiness $\left.=0.22\right)$. Models calibrated using VISNIRS were also calibrated using more PLS terms (LV 9 and 10), indicating that the Raman models calibrated in the current study may be more repeatable and robust. Zhao et al. [9] reported predictions calibrated using Raman for trained sensory panel chewiness, stringiness and cohesiveness (comparable to difficulty to swallow) scores with greater accuracy $\left(\mathrm{R}^{2} \mathrm{CV}=0.63 ; 0.63 ; 0.64\right)$ and lower error value $(\mathrm{RMSECV}=8.48 ; 2.98$; 5.93) than the current study, suggesting that homogenisation of the tissue (and subsequent destruction of muscle fibre formation) may improve the predictive ability of traits related to sensory toughness. Examination of the loading plots presented in Figure 1b, 1c and 1d identified a number of bands that contribute most to the prediction of tough sensory traits. Chewiness $\left(1661,1681 \mathrm{~cm}^{-1}\right)$, stringiness $\left(1680 \mathrm{~cm}^{-1}\right)$ and difficulty to swallow $\left(1666 \mathrm{~cm}^{-1}\right)$ were all prominent bands that positively correlate with $\beta$-sheet folding (with tougher meat having a greater amount of $\beta$-sheet structures) as discussed by Beattie et al. [3]. 
Raman predictions for crumbliness gave similar model performance to the other textural traits previously discussed $\left(\mathrm{R}^{2} \mathrm{CV}=0.36\right.$; $\left.\mathrm{RMSECV}=8.92\right)$. This model was constructed with the use of one LV and EMSC spectral pre-processing. While the predictive accuracy of the models is not very high, the fact that the model is in the first term indicates that it is quite stable. In previous research carried out by this group, crumbliness was predicted with VISNIRS with higher predictive accuracy $\left(\mathrm{R}^{2} \mathrm{CV}=0.41\right)$ and comparable RMSECV value (9.4); however, seven LV were needed to calibrate the best fitting model [7]. When comparing the two technologies, taking the slight difference in $\mathrm{R}^{2} \mathrm{CV}$ value and the large difference in number of LV used to calibrate the models, the data suggests that Raman spectroscopy may be a more repeatable and robust method of spectroscopy for the prediction of crumbliness.

\subsection{Prediction of Beef LTL Sensory Flavour and Juiciness by Raman Spectroscopy}

Best-fitting predictions for beef flavour provided the least accurate models, having an $\mathrm{R}^{2} \mathrm{CV}$ value of 0.22 and an RMSECV value of $6.36(1 \mathrm{LV})$ (Table 2). Previously, models were calibrated for beefflavour prediction by our group using VISNIRS. Unsatisfactory predictions with VISNIRS were found for this trait $\left(\mathrm{R}^{2} \mathrm{CV}=0.13\right.$; $\left.\mathrm{RMSECV}=6.4\right)$ [7], suggesting that spectroscopy on the intact muscle is not a useful mechanism to predict flavour.

Beef after-effect predictive models were slightly more accurate than beefflavour models in terms of higher $\mathrm{R}^{2} \mathrm{CV}(0.27)$ and lower RMSECV value (4.91), with the same number of $\mathrm{LV}$ used in calibration (one), indicating superior model robustness and repeatability.

The best fitting model for sensory panel juiciness scores predicted via Raman spectra gave an $\mathrm{R}^{2} \mathrm{CV}$ of 0.36 and a relatively low RMSECV of 5.63, constructed using two LV (Table 2). Interestingly, juiciness is one of only three traits in the current study where SG smoothing provided a more accurate model than EMSC. Fowler et al. [6] presented a similar predictive value for juiciness using an untrained sensory consumer panel $\left(R^{2} C V=0.42\right)$, however with a much higher margin of error $(\mathrm{RMSECV}=11.29)$ and with the use of more PLS terms $(\mathrm{LV}=5)$.

In the current study, models for the prediction of fatty mouthfeel and fatty after-effect were calibrated with a moderate degree of success (Table 2). Best fitting models for fatty mouthfeel provided an $\mathrm{R}^{2} \mathrm{CV}$ of 0.34 (RMSECV $=3.7 ; 1 \mathrm{LV}$ ). When comparing VISNIRS to Raman spectroscopy for the prediction of this trait, the best-fitting VISNIRS model only predicted fatty mouthfeel with an $\mathrm{R}^{2} \mathrm{CV}$ of 0.23 [7].

Fatty after-effect was predicted slightly more accurately in the current study than fatty mouthfeel $\left(\mathrm{R}^{2} \mathrm{CV}=0.44 ; \mathrm{RMSECV}=2.82 ; 2 \mathrm{LV}\right)$. Fatty after-effect is predicted with increased efficacy using Raman spectroscopy relative to VISNIRS as shown in [7], where the best-fitting model had a lower $\mathrm{R}^{2} \mathrm{CV}(0.28)$, increased RMSECV (3.2) and took 7 LV to calibrate the predictive model, indicating that the Raman model is the more robust and superior of the two.

The relationship between Raman spectra and trained sensory panel fatty mouthfeel and fatty after-effect scores are presented in Figure $1 \mathrm{i}$ and $1 \mathrm{j}$ by evaluating the loading plot values obtained for PLS factors 1 and 2. With respect to fatty mouthfeel, pronounced bands occur at $1680 \mathrm{~cm}^{-1}$ (Amide I), $1271 \mathrm{~cm}^{-1}$ (Amide III) and $1062 \mathrm{~cm}^{-1}, 1097 \mathrm{~cm}^{-1}$, $1122 \mathrm{~cm}^{-1}$ and $1130 \mathrm{~cm}^{-1}$ (C-C stretching modes) [23], while for fatty after-effect, bands are prominent at $1667 \mathrm{~cm}^{-1}$ and $1659 \mathrm{~cm}^{-1}$ (Amide I), $1271 \mathrm{~cm}^{-1}$ (Amide III) and $1032 \mathrm{~cm}^{-1}$, $1050 \mathrm{~cm}^{-1}, 1073 \mathrm{~cm}^{-1}$ and $1103 \mathrm{~cm}^{-1}$ [23]. Contribution of the region 1685-1645 $\mathrm{cm}^{-1}$ may be also associated with lipids such as the $\mathrm{C}=\mathrm{C}$ stretching mode occurring around $1680-1640 \mathrm{~cm}^{-1}$ [22]. Similarly, the intensity increase at $1130 \mathrm{~cm}^{-1}$ could be associated with C-C stretching modes of lipids [6].

Metallic flavour and metallic after-effect were positively correlated to each other [7], however in this study, the two traits were predicted with differing accuracies. Metallic flavour was more accurately predicted $\left(\mathrm{R}^{2} \mathrm{CV}=0.52 ; \mathrm{RMSECV}=4.08\right.$; two $\left.\mathrm{LV}\right)$, compared to metallic after-effect $\left(\mathrm{R}^{2} \mathrm{CV}=0.37\right.$; RMSECV $=5.94$; one $\left.\mathrm{LV}\right)$. This is not surprising, as sensory after-effects are by nature indirect and slightly removed from the actual eating experience. The prediction 
value achieved for this trait was three-fold greater than the result achieved using VISNIRS $\left(\mathrm{R}^{2} \mathrm{CV}=0.17\right.$; $\left.\mathrm{RMSECV}=4.38 ; 10 \mathrm{LV}\right)$, with eight fewer LV needed to calibrate a model. Indeed, even for metallic after-effect, the predictive models we obtained via Raman spectra were better than those obtained previously using VISNIRS $\left(\mathrm{R}^{2} \mathrm{CV}=0.19\right.$; $\mathrm{RMSECV}=6.6$; 10 LV) [7]. In Figure 1k, positive correlations can be seen between metallic flavour trained sensory panel scores and bands situated at 829, 853, 1002, 1128, 1450 and $1464 \mathrm{~cm}^{-1}$, while negative correlations exist between metallic flavour and the bands 842, 998, 1009, 1140, 1215 and $1432 \mathrm{~cm}^{-1}$. Correlations between Raman spectral bands and metallic after-effect are presented in Figure 11, with strong positive correlations between the trait and the bands at $885,1107,1199,1294$ and $1480 \mathrm{~cm}^{-1}$. Metallic after-effect was negatively correlated with the bands 1066, 1117, 1982, 1371, 1733 and $1749 \mathrm{~cm}^{-1}$. When comparing our results for prediction of beef sensory flavour and juiciness via Raman spectroscopy to the most similar (yet less industrially relevant in design) published studies, the predictions (for the most part) are within a similar range. Zhao et al. [9] presented predictions that were more accurate than the current study for the sensory traits; beef flavour, beef flavour length (comparable to beef after-effect), residual metallic (comparable to metallic after-effect in the current study) and fatty mouthfeel (comparable to the fattiness trait presented) ( $\mathrm{R}^{2} \mathrm{CV}=0.61-0.84$; RMSECV = 2.31-4.65); whereas Beattie et al. [3] predicted beef flavour in a similar fashion to the current study $\left(\mathrm{R}^{2} \mathrm{CV}=0.26\right.$; $\left.\mathrm{RMSECV}=7.74\right)$. Predictions obtained in this study for fatty after-effect were in the same range as the result obtained by Zhao et al. [9] for the comparable residual fattiness sensory trait $\left(\mathrm{R}^{2} \mathrm{CV}=0.54\right.$; $\left.\mathrm{RMSECV}=2.42\right)$. However, the predictions of metallic flavour in both studies are very similar $\left(\mathrm{R}^{2} \mathrm{CV}=0.54\right.$; $\left.\mathrm{RMSECV}=2.55\right)$. While the homogenisation of samples may aid the prediction of beef sensory flavour traits by Raman spectroscopy (e.g., homogenising fat, protein and flavour compounds within the sample), when looking across the full range of sensory flavour traits, decent predictions can be obtained without the need for homogenisation, leading to a more rapid, non-destructive technology with greater scope for the meat industry.

\section{Conclusions}

The results of this research demonstrate that Raman spectra collected from beef LTL samples have the potential to predict a wide range of trained sensory panel scores with varying levels of accuracy and margin of error, dependent on the trait. The most accurate coefficients of determination of cross validation calibrated within the current study were for the trained sensory panel textural scores; in particular tenderness, chewiness and stringiness, with practical predictions achieved for metallic flavour, fatty after-effect and juiciness. EMSC spectral pre-processing provided the best-fitting model for all but one trait evaluated in this study. Raman spectroscopy is a valuable tool for breeders and processors with regard to the prediction of beef quality as the spectra can be recorded non-destructively and rapidly, with potential for on-line application. Information can be captured on wide ranging and difficult to measure traits, once the calibrations are available. This study provides calibrations for valuable quality traits derived from a trained sensory panel in a non-destructive manner, using Raman spectra collected at a time-point compatible with meat management systems, and hence may have relevance to future breeding programmes for beef sensory quality.

Supplementary Materials: The following supporting information can be downloaded at: https:/ /www. mdpi.com/article/10.3390/chemosensors10010006/s1, Figure S1: Average spectra for five highest and lowest scoring samples for each of three sensory traits (a) tenderness, (b) chewiness and (c) crumbliness. Less favourable profiles in red and more favourable profiles in dashed blue for tenderness and crumbliness, while for chewiness, less favourable profiles are in dashed blue and more favourable profiles are in red. 
Author Contributions: Conceptualization, R.M.H., P.A. and T.S.; methodology, R.M.H., T.S., P.A., R.C.-M. and J.C.; data analysis, R.C.-M. and J.C.; draft preparation, J.C.; writing-review and editing, R.M.H., P.A., A.C., R.C.-M. and T.S.; project administration, R.M.H. and T.S.; funding acquisition, R.M.H. and T.S. All authors have read and agreed to the published version of the manuscript.

Funding: This work is funded by the BreedQuality project $(11 / \mathrm{SF} / 311)$ which is supported by The Irish Department of Agriculture, Food and the Marine (DAFM) under the National Development Plan 2007-2013.

Acknowledgments: We acknowledge the Irish Cattle Breeders Federation for access to samples, Carol Griffin and Carmel Farrell for conducting the trained sensory panel analysis and Eugene Vesey for his assistance.

Conflicts of Interest: The authors declare no conflict of interest.

\section{References}

1. Grunert, K.G.; Bredahl, L.; Brunsø, K. Consumer perception of meat quality and implications for product development in the meat sector-A review. Meat Sci. 2004, 66, 259-272. [CrossRef]

2. Troy, D.; Kerry, J.P. Consumer perception and the role of science in the meat industry. Meat Sci. 2010, 86, 214-226. [CrossRef] [PubMed]

3. Beattie, R.J.; Bell, S.J.; Farmer, L.J.; Moss, B.W.; Patterson, D. Preliminary investigation of the application of Raman spectroscopy to the prediction of the sensory quality of beef silverside. Meat Sci. 2004, 66, 903-913. [CrossRef]

4. Santos, C.C.; Zhao, J.; Dong, X.; Lonergan, S.; Lonergan, E.H.; Outhouse, A.; Carlson, K.; Prusa, K.; Fedler, C.; Yu, C.; et al. Predicting aged pork quality using a portable Raman device. Meat Sci. 2018, 145, 79-85. [CrossRef]

5. Prevolnik, M.; Čandek-Potokar, M.; Škorjanc, D. Ability of NIR spectroscopy to predict meat chemical composition and quality-A review. Czech J. Anim. Sci. 2011, 49, 500-510. [CrossRef]

6. Fowler, S.M.; Schmidt, H.; van de Ven, R.; Hopkins, D.L. Preliminary investigation of the use of Raman spectroscopy to predict meat and eating quality traits of beef loins. Meat Sci. 2018, 138, 53-58. [CrossRef]

7. Cafferky, J.; Sweeney, T.; Allen, P.; Sahar, A.; Downey, G.; Cromie, A.R.; Hamill, R.M. Investigating the use of visible and near infrared spectroscopy to predict sensory and texture attributes of beef M. longissimus thoracis et lumborum. Meat Sci. 2019, $159,107915$. [CrossRef] [PubMed]

8. Nian, Y.; Zhao, M.; O'Donnell, C.P.; Downey, G.; Kerry, J.P.; Allen, P. Assessment of physico-chemical traits related to eating quality of young dairy bull beef at different ageing times using Raman spectroscopy and chemometrics. Food Res. Int. 2017, 99, 778-789. [CrossRef] [PubMed]

9. Zhao, M.; Nian, Y.; Allen, P.; Downey, G.; Kerry, J.P.; O’Donnell, C.P. Application of Raman spectroscopy and chemometric techniques to assess sensory characteristics of young dairy bull beef. Food Res. Int. 2018, 107, 27-40. [CrossRef]

10. Damez, J.-L.; Clerjon, S. Meat quality assessment using biophysical methods related to meat structure. Meat Sci. 2008, 80, 132-149. [CrossRef]

11. Aalhus, J.L.; López-Campos, Ó.; Prieto, N.; Rodas-González, A.; Dugan, M.E.R.; Uttaro, B.; Juárez, M. Review: Canadian beef grading-Opportunities to identify carcass and meat quality traits valued by consumers. Can. J. Anim. Sci. 2014, 94, 545-556. [CrossRef]

12. Meisel, S.; Stöckel, S.; Rösch, P.; Popp, J. Identification of meat-associated pathogens via Raman microspectroscopy. Food Microbiol 2014, 38, 36-43. [CrossRef] [PubMed]

13. Scheier, R.; Bauer, A.; Schmidt, H. Early Postmortem Prediction of Meat Quality Traits of Porcine Semimembranosus Muscles Using a Portable Raman System. Food Bioprocess Technol. 2014, 7, 2732-2741. [CrossRef]

14. Andersen, P.V.; Wold, J.P.; Gjerlaug-Enger, E.; Veiseth-Kent, E. Predicting post-mortem meat quality in porcine longissimus lumborum using Raman, near in-frared and fluorescence spectroscopy. Meat Sci. 2018, 145, 94-100. [CrossRef] [PubMed]

15. Bauer, A.; Scheier, R.; Eberle, T.; Schmidt, H. Assessment of tenderness of aged bovine gluteus medius muscles using Raman spectroscopy. Meat Sci. 2016, 115, 27-33. [CrossRef]

16. Cama-Moncunill, R.; Cafferky, J.; Augier, C.; Sweeney, T.; Allen, P.; Ferragina, A.; Sullivan, C.; Cromie, A.; Hamill, R.M. Prediction of Warner-Bratzler shear force, intramuscular fat, drip-loss and cook-loss in beef via Raman spectroscopy and chemometrics. Meat Sci. 2020, 167, 108157. [CrossRef]

17. Cafferky, J.; Hamill, R.M.; Allen, P.; O’Doherty, J.V.; Cromie, A.; Sweeney, T. Effect of Breed and Gender on Meat Quality of M. longissimus thoracis et lumborum Muscle from Crossbred Beef Bulls and Steers. Foods 2019, 8, 173. [CrossRef]

18. AMSA. Research Guidelines for Cookery, Sensory Evaluation and Instrumental Tenderness Measurements of Meat; American Meat Science Association: Champaign, IL, USA, 2015; Available online: https://www.meatscience.org/docs/default-source/ publications-resources / amsa-sensory-and-tenderness-evaluation-guidelines / research-guide/2015-amsa-sensory-guidelines1-0.pdf?sfvrsn=6 (accessed on 5 May 2020).

19. Chong, I.-G.; Jun, C.-H. Performance of some variable selection methods when multicollinearity is present. Chemom. Intell. Lab. Syst. 2005, 78, 103-112. [CrossRef] 
20. Liu, R.; Zhang, W. Detection Techniques of Meat Tenderness: State of the Art. Meat Quality Analysis: Advanced Evaluation Methods, Techniques, and Technologies; Elsevier Inc.: Amsterdam, The Netherlands, 2019. [CrossRef]

21. Cama-Moncunill, R.; Gavaldà, M.P.C.; Cama-Moncunill, X.; Markiewicz-Kęszycka, M.; Dixit, Y.; Cullen, P.; Sullivan, C. Quantification of trace metals in infant formula premixes using laser-induced breakdown spectroscopy. Spectrochim. Acta Part B At. Spectrosc. 2017, 135, 6-14. [CrossRef]

22. Herrero, A.M. Raman spectroscopy a promising technique for quality assessment of meat and fish: A review. Food Chem. 2008, 107, 1642-1651. [CrossRef]

23. Socrates, G. Infrared and Raman characteristic group frequencies. Infrared and Raman characteristic group frequencies. J. Raman Spectrosc. 2004, 35, 905. [CrossRef] 